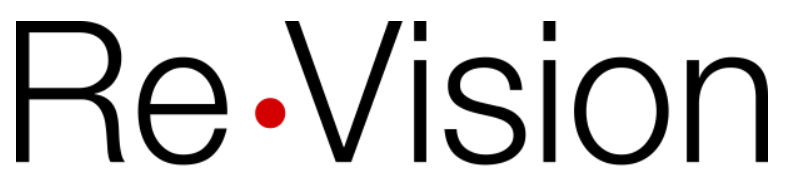

UNIVERSITY

of GUELPH

The Centre for Art and Social Justice

\title{
Difference within and without: Health care providers' engagement with disability arts
}

Katharine Viscardis

Trent University

Carla Rice

University of Guelph

Victoria Pileggi

University of Guelph

Angela Underhill

University of Guelph
Eliza Chandler

Ryerson University

Nadine Changfoot

Trent University

Phyllis Montgomery

Laurentian University

Roxanne Mykitiuk

York University

\section{Recommended citation:}

Viscardis, K., Rice, C., Pileggi, V., Underhill, A., Chandler, E., Changfoot, N., Montgomery, P., \& Mykitiuk, R. (2018). Difference within and without: Health care providers' engagement with disability arts.

Qualitative Health Research. https://doi.org/10.1177/1049732318808252 


\section{Difference Within and Without: Health Care Providers' Engagement With Disability Arts}

Katharine Viscardis, Carla Rice, Victoria Pileggi, Angela Underhill, Eliza Chandler, Nadine Changfoot, Phyllis Montgomery, Roxanne Mykitiuk

\section{Abstract}

$\mathrm{Re} \cdot \mathrm{Vision}$, an assemblage of multimedia storytelling and arts-based research projects, works creatively and collaboratively with misrepresented communities to advance social well-being, inclusion, and justice. Drawing from videos created by health care providers in disability artist-led workshops, this article investigates the potential of disability arts to disrupt dominant conceptions of disability and invulnerable embodiments, and proliferate new representations of bodymind difference in health care. In exploring, remembering, and developing ideas related to their experiences with and assumptions about embodied difference, providers describe processes of unsettling the mythical norm of human embodiment common in health discourse/practice, coming to know disability in nonmedical ways, and re/discovering embodied differences and vulnerabilities. We argue that art-making produces instances of critical reflection wherein attitudes can shift, and new affective responses to difference can be made. Through self-reflective engagement with disability arts practices, providers come to recognize assumptions underlying health care practices and the vulnerability of their own embodied lives.

\section{Keywords}

arts-based research, health care, embodiment, disability, vulnerability, critical reflexivity, qualitative, multimedia story-making, Ontario, Canada 


\section{Introduction}

To watch the stories presented in our article, go to https://projectrevision.ca/differencewithin-and-without. Following the prompts, enter the password "withinandwithout." Please note: these videos are intended for readers and for viewing in educational settings and are not for public screening. (See Haigh \& Hardy, 2011; Rice, 2018; Rice \& Mundel, 2018; Rieger \& Chernomas, 2013; Treloar, McMillan, \& Stone, 2017, for ideas on how to use digital stories in the classroom.)

In this article, we examine the potential of the arts to unsettle the mythical norm of liberal human embodiment-the rational, autonomous, invulnerable subject-that is foundational to health care and informs health care practice. We propose that multimedia storytelling, within video-making workshops, offers health care providers the opportunity to re-imagine disability. Bringing together literatures on disabled embodiment and human vulnerability, critical reflection in professional practice, and the transformational potential of art-making, we analyze eight multimedia stories created by health care providers in our project's video-making workshops. Our goal in these workshops was to explore how multimedia storytelling can generate new knowledges that carry the potential to shift clinical concepts of bodymind difference. If disability theory offers "a philosophical challenge to conventional liberal assumptions" about what constitutes normative personhood (Devlin \& Pothier, 2006, p. 16), then disability art practice can be understood as a critically reflective medium through which this challenge might materialize. We examine instances of critical reflection in the videos produced by health care providers in disability-artist/academic-led workshops. We argue that reflective art-making can shift providers' responses, clinical competencies, and affective responses to bodymind difference. Through engaging with the arts in disabilitypositive spaces, practitioners recognize assumptions underlying health care practice, and the vulnerability of their own embodied lives. This altered understanding of embodiment has the potential to transform the quality of care provided to disabled people. 


\section{Beyond the Liberal Humanist Subject}

Fiona Kumari-Campbell (2001) describes ableism as a system of "beliefs, processes and practices that produces a particular kind of self and body (the corporeal standard) that is projected as the perfect, species-typical and therefore essential and fully human. Disability then is cast as a diminished state of being human" (p. 44). The categorization of certain bodyminds as diminished is not natural but has emerged historically through the union of Enlightenment humanism with liberal ideology (Pierre, 2015, pp. 331-332). Together, such theories have come to define the contours of the liberal humanist subject—rational, autonomous, transcendent, and invulnerable —and to construct a normative standard of the human. This species' typical standard reproduces ableism by casting persons who fall outside its constrictive boundaries as immanent, uncontrolled, incapable, or "Other" (Rice, Chandler, Liddiard, Rinaldi, \& Harrison, 2018). These Others, as posthumanist philosopher Rosi Braidotti (2016) stresses, "embody difference as pejoration, and their differences get organized on a hierarchical scale of decreasing social and symbolic worth" (p. 381). The liberal humanist subject, insofar as it is imagined as an autonomous moral agent whose embodied reality is one of invulnerability, has dangerous consequences for those who do not conform, specifically in the denial of their personhood (Shildrick, 1997).

To redress this problem, body philosopher Margrit Shildrick argues that liberal humanist understandings of the human must be abandoned. Instead, "the body beyond biologic, universalist and normative presuppositions" must be reconstituted to reflect its fluid, "leaky," and ever-changing reality (Shildrick, 1997, p. 216). Yet this reconceptualization is far from an easy task. As legal philosopher Martha Fineman (2008) explains, the liberal humanist subject and its "imperfect" Other may be fictive, but it is a fiction upon which major western social systems have been built, shaping law, government, and policy, and governing the organization and operation of our most important institutions, including health care systems. Within health care, discourses of disability as abnormal, vulnerable, and contaminated/ing forms of embodiment operate on an institutional level, shaping its knowledges and practices. For ethics scholar Therese Lysaught (2009), discourses are "incarnated in social practices [that] define the rules for practices, which 
in turn enact those discourses vis-à-vis individual bodies" (p. 391). Applying Lysaught's insight to western health care logics and interactions invites questions about how cultural values collude with biomedical discourses to produce harmful medical "truths," which frame certain embodiments as ordinary/expected and others as perplexing/problematic biomedical deviations (Rioux \& Valentine, 2005; Titchkosky, 2012). These assumed truths (discussed in our analysis) reinforce a medicalized binary of the invulnerable expert practitioner and the vulnerable disabled Other, and perpetuate the cure imperative (Rioux \& Valentine, 2005). Lysaught's line of inquiry further provokes consideration of ways that health care providers might contend with/respond to biomedical framings of human variation in their clinical practice using critical reflection.

From a social theory perspective, critical reflection involves an "analysis of perceptions, cultural assumptions and social expectations that dictate how humans relate to the world" (Mezirow, 2000, as cited in Crowe \& O'Malley, 2006, p. 81). This process offers one pathway for health care providers to dismantle taken-for-granted framings of difference that drive social and health care relations (Rice, 2018; Rice, LaMarre, Changfoot, \& Douglas, 2018). Furthermore, it enables providers to interpret "power relationships that allow, or promote, one particular set of practices over others" (Brookfield, 2009, p. 294). Critical reflection also entails that health care providers commit to sustained inquiry about whose interests are being protected and elided by various modes of practice. Beyond practice, critical reflection has implications for changing cultures and systems. Pedagogy researcher Stephen Brookfield notes that critical reflection "focuses not on how to work more effectively or productively within an existing system, but on calling the foundations and imperatives of the system itself into question, assessing their morality, and considering alternatives" (Brookfield, 2009, p. 297). As such, it involves both significant unlearning and unique transformations initiated by what he refers to as a "disorienting dilemma" (p. 295)_an event through which providers become conscious of discrepancies between their assumptions and what actually takes place. Disorienting dilemmas, in turn, invite four iterative change processes: naming assumptions, testing assumptions, searching for alternatives, and 
finally, enacting alternatives. In this way, critical reflection might encourage providers to recognize, challenge, and transform ableist assumptions that underpin their practice and institutional contexts. Moving beyond acknowledging the presence of harmful stereotypes, critical reflection invites deeper engagement in dialogues about alternative orientations respectful of Others. McCabe and Holmes (2009) argue that disrupting ideologies destabilizes power inequities they uphold-in professional encounters and in the organization of institutions-thus helping to achieve disability studies' goals of disability liberation.

Arts-based research provides an avenue for moving critical reflection into practice. Health care providers' engagement with the arts (as creators and audiences) is an effective medium for reflection as art can elicit disorienting dilemmas and facilitate knowledge-making (Boydell et al., 2012). By fostering deeper understandings (Bergum \& Godkin, 2008) and challenging positivist knowledge systems, art has the potential to produce counter-hegemonic meanings (Trevelyan, Crath, \& Chambon, 2014). Art can serve as a problem-solving medium in animating and addressing injustices (MacDonnell \& MacDonald, 2011). In particular, disability arts, an emergent arts sector in Canada that jointly cultivates art created by disabled people and works to establish disability cultural practices to make culture more inclusive, can trouble liberal notions of "humanness" and re-imagine what it means to be human (Chandler, Changfoot, Rice, LaMarre, \& Mykitiuk, 2018; Changfoot \& Rice, in press; Rice et al., 2017; Rice, LaMarre, \& Mykitiuk, 2018).

We argue that the self-reflexive videos made by health care providers in our disability arts-informed research project offer rich representations of the complex inter- and intrarelational experiences that provoke providers' shifting orientations toward bodymind difference. These shifts in orientation are not in the form of new standardized rules and practices substituting for the old ones that the videomakers call into question, but in the form of self-reflective narrative. Each narrative centers a problematic dimension of health care practice identified by the storyteller and offers an aesthetic rendering of that problem using poetry, image, voice, ambient sound, music, and movement. 


\section{Fostering Critical Reflection Through Disability Arts}

The Re•Vision Centre for Art and Social Justice, a research creation center at the University of Guelph in Ontario, Canada, offers the methodology, equipment, and artistic expertise for making the videos featured here. At the heart of Re•Vision's approach is the "coming together of storytelling and social change"-the creating and sharing of new understandings of difference that disrupt dominant narratives and open possibilities (Rice \& Mundel, 2018, p. 215). We take a multimedia narrative approach adapted from digital storytelling, a method developed in the mid-1990s by the StoryCenter in California, as a digital reworking of the live theater and radio genres of autobiographical monologue (Lambert, 2013). Although many terms have emerged for referring to community-based story- and video-making methods, we use the terminology multimedia story-making (Rice \& Mundel, 2018). "Multimedia" encompasses the diverse media forms, and "story-making" places emphasis on the constructivist, storied nature of knowledge claims.

For this project, we, the project's researchers, invited disabled people and health care providers to engage in multimedia story-making around the theme of changing conceptions of disability in health care (Rice, Chandler, \& Changfoot, 2016; Rice, Chandler, Harrison, Ferrari, \& Liddiard, 2015; Rice, Chandler, et al., 2018; Rice et al., 2017). From 2012 to 2015, we ran 10 multimedia video-making workshops in three regions of Ontario: four workshops with adults with disabilities, four with health care providers (both disabled and nondisabled), and two training workshops with our multidisciplinary research team (which included disabled, nondisabled, and provider researchers). In these workshops, participants learned how to make multimedia stories - two- to three-minute videos that pair personal narratives with video, artwork, music, photos, and more (Rice \& Mundel, 2018). In total, we produced more than 100 videos related to investigating and changing conceptualizations of disability that we have subsequently screened widely in health care settings and beyond. The workshop and research process were approved through the University of Guelph's Research 
Ethics Board (REB\# 12AP010). Participants were able to provide different levels of consent regarding the sharing of their stories, including whether or not their story could be screened, used for research, and/or not used at all.

Thirty-eight health care provider participants (12 nurses, 16 social worker-counsellors, six occupational therapists, three doctors, and one personal support worker) participated in the workshops. The health care provider participants were at different stages of their career, and included providers-in-training, those currently practicing in clinical or educational settings, and those identifying as former practitioners.

Participants were recruited through snowball and purposive sampling via health care professional networks of research team members. Workshops were designed for up to 12 participants and took place over the course of 2 to 3 days in institutional (hospital) and community (service organization) spaces. These locations were chosen to facilitate provider participation and give storytellers direct access to spaces, sounds, and props that could be relevant to their storytelling. Disabled and nondisabled researchers received immersive training in video-making prior to co-leading the workshops. As part of this process, many made their own self-reflective videos (Rice, LaMarre, Changfoot, \& Douglas, 2018; Rice \& Mundel, 2018) and some also identified as members of disability arts communities beyond the project (Chandler et al., 2018; Rice, LaMarre, \& Mykitiuk, 2018; Rice \& Mundel, in press).

The trained workshop facilitators introduced participants to disability studies and disability arts perspectives and invited them to reflect critically on conceptions of disability in health care, mining their professional and/or personal experiences for insights. Through a story circle, participants shared their reflections around an experience or moment they chose to develop into a video. The workshops also featured small group and individual tutorials on creative writing and using audio, video, and editing software and equipment, and full technical, writing, and conceptual support assisted participants' move from reflection to script development to finished video. As this research progressed, the workshops became vibrant spaces for incubating disability arts practices and community (Chandler et al., 2018; Rice, LaMarre, \& Mykitiuk, 
2018; Rice \& Mundel, in press). Such cultural production moves beyond a social model of disability, which advocates primarily for the removal of barriers, by advancing disability culture through cultivating art-making practices of disabled people as creators, leaders, and participants in artistic work.

To push against reproducing ableist dynamics in our interpretive process, our team of disabled and nondisabled researchers (including some of the authors) and some workshop participants engaged in a double hermeneutic. Similar to video-reflexive ethnography discussed by Carroll and Mesman (2018) and Dadich, Collier, Hodgins, and Crawford (2018), this involved watching and discussing the videos as a way of registering our affective reactions to and thoughts on possible meanings and symbols embedded in them, which animate intimate aspects of life. We then discussed our interpretations as researcher-facilitators and as story-makers. In addition, since we worked closely with storytellers in creating their work, we drew on our knowledge of the aims and intentions they expressed during workshops to strengthen our analyses of their stories. In this way, the workshop was a research-creation space and a space in which analysis of the work was collaboratively generated (Rice, Dion, Mundel, \& Fowlie, in press). We refined our initial interpretations of participants' artistic outputs using content analysis methods (Braun \& Clarke, 2006; Drisko \& Maschi, 2015). These analytical activities reveal providers' experiences of vulnerability, critical reflection, and disorienting dilemmas as represented in their stories. We generated three questions through our engagement with the completed provider videos: "How do these storytellers story their knowledge of disability?" "In what ways do their stories realize the goals of critical reflection?" and "How do storytellers implicate systems of power in reproducing hegemonic ideas about disability?" All 38 provider stories were analyzed using this guiding framework; however, for the purposes of this paper, we selected eight stories that provide particularly rich responses to our inquiries.

\section{Differences Within and Without}


Our analyses of provider stories surface two distinct yet overlapping thematic directions in the stories: reflections on differences "within" and "without." Stories of differences "within" tell of embodied histories of disability/difference and how these have shaped storytellers' lives. These stories move past the personal as storytellers who identify in some way as "disabled" or "different" and struggle to hold onto their identities as health care providers in light of perceived irreconcilability between embodied identities culturally coded as vulnerable (disabled persons) and identities deemed as invulnerable (health care providers). We understand these works as snapshots of the makers' experiential knowledge of disability and of health care systems/practices—of knowledge condensed into a few moments after careful reflection (Rice, Chandler, et al., 2018). The "within" stories invite viewers to consider who is the expert in the storytellers' videos: the disability-identified storyteller, speaking openly about their disability, or the provider-storyteller aware of professional/patient, nondisability/disability binaries? How do these personal-professional identities coexist? In contrast, stories "without" center relational more than first-person knowledge. In stories "without," storytellers critically reflect on their positioning as normatively embodied health care providers in intimate and reciprocal relationships with non-normatively embodied people. They describe ways that systems dehumanize those with complex embodiments even as storytellers express commitment to the provision of accessible, respectful care. Together, the stories surface knowledges central to understanding disabled bodies as indivisibly connected to humans with emotions, interests, identities, and capacities of their own, which are often unacknowledged within health care systems.

As this line of analyses developed, we found that the distinctions between "within" and "without" began to blur: storytellers did not situate bodymind difference wholly in or outside either their personal or professional selves; rather, difference often emerged in the spaces in-between personal and professional, self and other/world. This emergence of difference in-between makes sense if we think about disability through a new materialist lens, as materializing in relationships between bodies and worlds, as neither purely of bodies nor of contexts but as produced in their confrontation (Rice, 2014). While we recognize disability's fluidity and instability and people's movement in 
and outside of the category, we remain alert to the dangers of affirming all experiences as equally "different," which collapses real discrepancies in power, position, and experiences of ableism (intersecting with other oppressions). For this reason, we maintain the distinction between the types of knowledge elicited through storytellers' narrating of differences "within" and "without" even as we assert that both contributed to self and social discovery and to the blurring of boundaries between disabled and nondisabled identities and worlds. In the sections that follow, we describe providers' "within" and "without" views of disability/difference through their embodied and relational experiences.

\section{Difference Within}

In The Autumn of 2010, nursing professor and former nurse Gail Lindsay comes to an embodied understanding of chronic pain, an experience she introduces with an excerpt from an Emily Dickinson poem. Lindsay narrates the sense of being "exquisitely stopped in place," as her sudden encounter with chronic pain helped her to understand "for the first time ... how this kind of suffering makes people want to die." Images of inkblots running down the screen illustrate the pain that radiates through her left leg into her toes. Lindsay's view of the world (and angle of the camera) literally upends as she lays in the passenger seat while being driven to physical therapy appointments; the horizon where sky joins the earth disappears, and her focal point turns skyward, giving her a new disability or "cripped" vantage point. Lindsay takes her cripped perspective into the health care system by refusing the system's construction of disability as Other, implying negative consequences of being interpolated as such. Her statement, "I was sure I didn't want to go on disability leave," is followed by the sound of a river gushing, creating a sensation of being overtaken or overwhelmed by a force beyond her control. In not taking a disability leave, she resists the label of disability and its implied precarity in the workplace; instead, she seeks to slow, perhaps even contest, the "insolvency of her body" by focusing her energy on tasks she deems necessary for survival. Moving from physicality, from the embodied sensation of pain, Lindsay offers us an emotive and political understanding of suffering; as an image of her mirror's reflection appears and transitions from grayscale to color, she poses two poignant, albeit satirical, questions: 
"What was the straw that broke my back?" and "What does my body know that I need to wake up to?"

In My (Im)Possible In/Vulnerability, nursing professor and former nurse Hilde Zitzelsberger explores the multiplicity and incongruity of her embodied identities, surfacing contradictions surrounding vulnerability and oppression. Just as her story is framed as a series of perplexing questions, so too are the accompanying visuals organized as a series of murky photos of sepia-toned body parts coming in and out of focus, layering one on top of another. Zitzelsberger interrogates and subverts the seemingly rigid boundary between "messy/problematic" bodies and "controlled/masterful" ones, exploring how we each are made to occupy only one side of this binary. Seeking to destabilize categories of identity and the polarizing logics that reify the very boundaries she seeks to deconstruct, Zitzelsberger asks, "what side of the bed, lectern, or desk am I supposed to be on?" She questions the mutual restrictiveness of caring and being cared for, teaching and being taught, studying and being studied. She describes her oscillation between vulnerability and invulnerability by reflecting on how feelings of self-assurance generate a sense of attractiveness, while fears of exposure produce its counterpoint. Her final line, "I feel so much self-judgment when I reveal my failures, shame when I reveal my imperfections. But I feel so alive in my skin when I do," suggests movement across the chasm of in/vulnerability, and points to the risks and rewards of doing so.

In her video, Untitled, social worker Terri-Lynn Langdon reflects on what it means to be dis/abled (the word she chooses for her self-identification) as a health care provider, opening her video with a black and white clip of herself walking toward the camera in a way that makes her disability apparent. As she recounts the violence she experienced early in life, photos of her child-self appear and fade into one another, always zooming in on her face. The narrative shifts to seemingly happier memories, such as playing doctor and being cast as patient, a role she describes as "the star of the show." While she initially found pleasure in the play, Langdon tells of coming to realize how playing patient was neither coincidental nor benign: premised as it was on "fixing" her disability, 
the game created an impossible end-goal for her. She illustrates how she switches positions between desiring and rejecting normativity with clips of her travelling up and down, alone, through hospital hallways. As footage of Langdon walking toward and away from the camera rolls on screen, she narratively considers how she can pass as nondisabled in her professional work in certain situations, for example, when a client meets her when she is already sitting down. Langdon reflects on how she oscillates between desiring and rejecting normativity, and how being marked as disabled or nondisabled can, respectively, legitimize or invalidate her professional identity. She recalls one such pivotal moment in practice when a client who read her as nondisabled was startled by the sudden appearance of her disability. She ends with final reflections on her ability to "switch places" by choice and circumstance, as she "walks, wheels, sits; travelling through life as Terri-Lynn."

Nursing student Sarah Banani seeks to reconcile her complex embodiment with discourses about who healthcare providers are "supposed" to be in her video Untitled. Banani multiplies and rotates a single, medically-labelled image of a brain on the screen in different colors as she unpacks how her mind looks and works. She identifies an "outlier" in her mental test results, though she does not specify what tests she is referring to, or what this outlier is. She describes a disparity between the normative structure of the brain and chaotic reality of her outlier mind using visual analogies: although the brain is "supposed to keep all its important papers in folders in file cabinets... wear a suit and tie [and] tell a story that goes from A to Z," her mind instead stores information "in buckets and webs" and "secret cupboards," transmitting messages like "unscheduled fireworks." Banani tells us that she's sharing this story to discover the possible benefits of having a "messy mind," particularly as she enters nursing, a profession traditionally associated with tidiness, organization, attention to detail, and quick-thinking. Although she refers to a time in which she attempted to correct her unique ways of remembering to appear competent and effective, she ends her story on a note of acceptance. She resolves to use her unique ways of thinking/feeling to enhance her practice, as a bridge between self and others, as a 
reminder to see beyond what is expected, and to recognize value in others' differences, as she has in her own.

\section{Difference Without}

In her video, Untitled, personal care worker Julia Phillips interrogates her own institutionally driven practice with disabled people with complex health care needs. The story opens with a drawing of a single bed on a blank piece of paper that becomes animated as Phillips describes how she would perform her duties. More beds appear, and arrows are drawn between them, symbolizing Philips' monotonous movement of going from one "patient" to the next in providing them with "assembly line care." "We put each person in the same type of gown and 'diaper' and left them in bed," she explains. Philips later asserts, "I assumed that was normal." In the next scene, Phillips reveals that the normality of "assembly line care" remained a pillar of her professional practice until she met Joanie. Music begins to play as an image of Joanie appears. The viewer experiences a dramatic shift in tone, imagery, and language. Phillips recounts the similarities she had with Joanie and how they seemed to "click." Despite these similarities, it was not until Julia brought Joanie into her mother's home and helped Joanie transfer from her wheelchair to a living room chair that Julia finally "saw [Joanie] as the individual she was." This moment highlights an unsettling moment wherein Phillips realizes that the institutional practices she carried out were dehumanizing the people she worked and cared for. Phillips shares, "she had a voice, and I needed to hear her voice." In this statement, she recognizes Joanie and herself as active agents of change; through listening to Joanie, Phillips learns to challenge the institutional scripts that previously informed her support practices.

Phyllis Montgomery's video, Tables, addressed her experience of bodymind difference by contrasting a series of hallmark events at personal and professional tables. The first table is depicted as a desired place for school-aged Montgomery who would wait for an invitation to join her grandmother at the walnut dining room table in front of a large window. In this scene, a human silhouette appears in the distance outside of the window. Montgomery shares that it was in these moments that her grandmother 
disclosed the concealed differences of passing neighbors with a reminder that "this doesn't leave the table." The next series of tables illustrate adult Montgomery's professional engagement with others poignantly captured through hand-drawn sketches all including a table. Early in her career, the table in the nursing station is characterized as a "barrier to patient care" as it is located behind plexi-glass. Time passes, and nurses continue to sit behind glass, yet at the contemporary table, their focus is often on computer screens, a physical barrier for interactions with others. Down the hall from the nursing station, bedside tables in the patients' rooms are illustrated. In the medical unit, the bedside table holds flowers and get-well cards, hopeful messages of recovery. In contrast, the bedside table in the acute psychiatric unit is often empty. Its surface is used by a nurse to hold cups of pills. In the home of a client discharged from inpatient psychiatry services, the table is covered with personal belongings and serves as a welcoming space for interactions about recovery. Montgomery's portrayal of her time spent at tables in a professional capacity allowed her to witness the vulnerability of others. Her next illustration represents her own vulnerability at a grand and formal table within her workplace. Montgomery, at one end of this expansive table, is distanced from the dialogue of others, self-questioning her belongingness with their ideology. Gazing out the bank of large windows, she communicates awareness of her difference-she becomes the silhouette.

The notion of judgment also haunts nursing instructor and retired nurse Cathy Graham's video, Telling. As images of young women in starched white uniforms appear on screen, Graham describes what it was like to be trained as a nurse 40 years ago, when words like "religion," "order," "routine," and "compliance" were common vocabulary. She relays that "the sisters" responsible for training nurses did not tell them everything they needed to know, yet she clarifies, "telling, as a way of learning, is flawed anyway." As Graham chronicles her nursing path, she relates a particular challenge she faced when young women would come to her seeking pregnancy tests, hoping they would be negative. Graham critically examines her desire to educate young women about birth control unearthing a foundational trigger: the memory of her sister's unplanned pregnancy. An image of Graham and her sister as children appears and reappears several times as 
Graham describes the shame and secrecy surrounding her sister's pregnancy. Graham's final thought, "caring nurses are wounded healers," is followed by an image of her lush garden and the words "my healing place." Even though her advice-giving initially appears to come from without-from her military-like nursing education and health care encounters with young women-Graham's story is also one from within as she vicariously shared in her sister's and family's shame and secrecy. Graham has no substitute to offer for advice-giving, but rather, she shares her learning that advice is flawed and cheaply given, and that she herself is a wounded healer.

The final story, Go Home, by occupational therapist Isabella Cheng, surfaces the vulnerability of a loved one from the complex, dual positioning of family member and health care provider. The story begins by panning around the image of a woman's troubled face, starting at the top and slowly pulling back until the whole face is visible. As the image pulls back, we learn that Cheng was forewarned about her grandmother's (Badi-mommy's) cancer diagnosis, while her Badi-mommy was simply told, "Go home. Rest. Eat well. Sleep well." In this moment, Cheng's health care provider identity is shaken, while her granddaughter identity is thankful. The "gift," as she comes to know it, of Badi-mommy not knowing her diagnosis for 15 days, allows Cheng and her family to come together and "steal moments away" from the cancer that ultimately took Badimommy's life. As long, low notes sing from an instrument, serene landscapes flash on the screen. In 15 days, the family could prepare and treasure each moment with Badimommy without her being fraught with worry about the challenges to come. Suddenly, moving to an aural scene where she and Badi-mommy are with the surgeon, the calm images halt with crashing noise and blackness. Fire burns as Cheng shares what the surgeon relayed: "You'll go home, you'll wither away, and you'll die." As the fire crackles louder, Cheng expresses feelings of rage, hopelessness, and disgust. The surgeon's matter-of-fact delivery of the prognosis forces Cheng to think about her own work and how it is possible that she, too, has shared difficult news without compassion. For the remainder of her story, an image of she and Badi-mommy moves across the screen as Cheng questions her own identity as a health care provider and wonders how compassion might transform care, asking, "How do I bring caring back into our care?" 


\section{Theorizing the Difference That Difference Makes}

In analyzing these stories, we identify disorienting and reorienting dilemmas in the video-makers' personal and professional lives. We ascertain the production of new knowledge through self-reflection in each video that is at once thoughtful and feeling, and that challenges received narratives of disability/difference, albeit in diverse ways. We discuss these disorienting and reorienting dilemmas and consider the impact they have on the subjective experiences and knowledges of health care provider storytellers.

\section{Disorienting and Reorienting Dilemmas}

We begin our analysis with disorienting dilemmas, moments or events that call attention to the discrepancy between providers' taken-for-granted truths and their embodied confrontation with the world. Rethinking engrained truths entails engaging in transformative processes of identifying and assessing assumptions to create social and institutional change. Although the stories presented are diverse, each storyteller centers her story on one, or on the collision among multiple, disorienting dilemma(s). The dilemmas narrated relate moments wherein storytellers become aware of their own or others' bodymind differences, which they starkly contrast with the ways they have previously experienced and/or understood embodiment. These disorienting dilemmas, or unsettling moments, are often witnessed as storytellers encounter a conflict between what they are coming to know, and what they have previously known to be true because of their professional/institutional learning.

Lindsay's disorienting dilemma occurs as she experiences her body's vulnerability due to chronic pain. She comes to perceive quality of life in its absence and, for the first time, contemplates whether chronic pain and suffering might cause a person to take his or her own life. As Lindsay experiences shifting sensations of pain and nonpain, she reorients to embodiment as a continuous process of change and adjustment, recognizing her own bodily experience now as transient, volatile, and vulnerable, and 
disability as an othering workplace category to forswear. Banani's training compels her to rethink bio-medical views of messy minds as limiting and disordered. Zitzelsberger demonstrates "embodied reflexivity" (Burns, 2003, as cited in Sharma, Reimer-Kirkham, \& Cochrane, 2009; Rice, 2009), and contends with the vulnerability that comes with acknowledging herself as an embodied being who needs to be cared for as she is caring for others, and how this necessarily disrupts her practices and also leads to a more honest way of providing health care. Langdon's practice challenges assumptions about health care providers' embodiments, particularly those that equate any deviation from the norm with professional incompetence, even, or especially, when working with a client who calls her professional abilities into question. These stories attend to demands placed on health care providers to embody cultural ideals of rationality and invulnerability (Fineman, 2008; Shildrick, 1997), informed by biomedical and liberal humanist assumptions about normative personhood. While such dilemmas raise ethical questions regarding professional practice standards, we do not analyze them as ethical conundrums, make judgments, or draw conclusions about storytellers' ethical decisionmaking processes. Instead, we acknowledge the disorienting moments and the potential power of disorientation to elicit critical reflection. The ethical conundrums raised in the stories will be taken up in another article.

The storytellers also rely on their relational knowledge-their reflections on exchanges with those living with difference-to rethink difference and consider the influence such rethinking might have on their professional philosophies and practices. By welcoming Joanie into her mother's home, Phillips is jolted into recognizing Joanie's personhood. In making the connection between her desire for pre-empting young women's experiences of pregnancy to her own witnessing of her sister's experience, Graham learns to listen rather than to tell, rejecting the moralizing instructional practices that, as she suggests, might still characterize the field of reproductive counselling. In narrating her late Badi-mommy's diagnosis of terminal cancer, Cheng invites us to consider the difference that consciousness of the other makes in health care provision and how she, and we, might engender such an orientation in interactions. Montgomery's disorienting moment is captured when she recognizes the human behind the psychiatric survivor 
table, a person who is not just a patient. All these storyteller accounts reveal shifts in perspective and reflections on practice and the discourses that inform it, particularly in relation to those culturally regarded as "not quite" or less than fully human.

These moments "disorient" in that they have the potential to unsettle or undo biomedical and liberal humanist assumptions about normativity and disability-assumptions that are foundational to social institutions and that have rippling effects and implicationswhether in relation to the storyteller themselves or to others. Disorienting moments, during which powerful discourses can be disrupted and challenged, are important starting points for broader processes of social transformation. One possible outcome of such disruption is the space that this opens for new conceptualizations of human embodiment to emerge, including more affirmative concepts of non-normativity around which institutions can positively reform.

\section{Reflective-Feeling Knowledge}

Feeling knowledge emerges from "qualitative nuances of situations" (Eisner, 2008, p. $10)$ conveyed in the storyteller videos. That is, the provider experiences occur not only within the blurred boundaries and identities between nonprovider/provider, nondisabled/disabled, invulnerability/vulnerability but also in a multisensory format of knowing, telling, and sensing. Storytellers represent their experiences in evocative, metaphorical, visual, auditory, kinesthetic, and emotive ways. Examples of "feeling knowledge" are evident in the poetry Lindsay recites to iterate her pain; in the analogies Banani offers to materialize her ways of thinking; in the inflection of Langdon's voice when she describes her opposition to the "fixing" game; in Zitzelsberger's nervous, confident laughter that bookends her story; in Cheng's manipulation of Badi-mommy's photos; and in Phillips' evocative images of Joanie. The creators' composition of layered elements of their stories influences their and our experiential knowledges of selves and others. They move past positivist and humanist understandings toward new understandings of their, and our, embodied vulnerabilities. The process is demonstrated by storytellers' purposeful inclusion of particular words, images, and sounds. The careful organization of these symbols contribute to the pace of the story, and, in the 
process, to distill and densify the elements into a mood, message, moment. The genre creates intimacy through the storytellers' voice, laughter, and breathing layered over personally meaningful photographs, through visuals and video clips, and through dedications, light, and other sensory effects that communicate and affect tacit thoughts and feelings.

As evidenced in the multimedia stories, feeling knowledge through art occurs through four possible pathways. First, the multimedia stories capture qualitatively much more than what may be communicated intellectually or in the written word alone by offering alternative conduits to imagine the world and to communicate knowledge-experience. The medium invites storytellers to center their embodied subjectivities, and allows them to translate feelings, sensations, and affects into aesthetic forms that otherwise are difficult to convey. Audiences can resonate with the experience of the maker and tap into their own emotions when viewing a video. The storyteller, in all their complexity, is brought to life and can be seen, heard, and sensed in layered ways. Second, in providing space for "feeling knowledge" to emerge, storytelling can facilitate empathetic understandings/relationships between practitioners and clients in that it, as Eisner (2008) notes, lays the groundwork for mutual recognition and shared meaning making by orienting the storyteller to difference and vulnerability within and without, and by orienting audiences to the human experience of the storyteller. Third, insofar as reflective art-making asks creators to imagine their possible selves, it can build affective ties between client and practitioner. Eaton and Donaldson (2016) found that nursing students reported attitude transformation toward older adults after being asked to reflect critically on how they themselves may experience aging. Similarly, citing Linda Finlay (2005), Sharma et al. (2009), in their study on researcher embodiment, show that "embodied intersubjectivity" (p. 1653), between researcher and researched, can create an "empathic connection" (p. 1653). Through multimedia storytelling, storytellers are offered space to examine their own or others' vulnerable embodiments, thus also potentially flexing and expanding their empathetic capacities. 
Finally, the production of feeling knowledge, and thus the creation of more intimate relationships, allows practitioners to critically reflect on the power dynamics that shape their encounters with others, and call into question the logics of categorization that allow one group to determine what another requires. This challenge to existing power relationships, as witnessed in our provider stories, often arises from the intimate relationships health care providers have with others. The feeling-knowledge that materializes through multimedia storytelling disrupts these sorts of power relations and boundaries; if storytellers understand their own or colleagues' practices as harmful to themselves and intimate others, they may come to recognize the logics underpinning their practice and refuse to endorse certain ways of working.

\section{Countering Received Truths}

The videos highlight the potential of health care provider multimedia story-making to counter taken-for-granted medical truths by revealing and disrupting three mutually sustaining health care discourses typically guiding health care provider practice: (a) that disability is an individualized, biological state requiring cure; (b) that directive, paternalistic, and impersonal approaches to care are best practice; and (c) that to be professional is to embody the normative, invulnerable, liberal humanist subject (Clare, 2017). Storytellers do not proffer substitute replacement rules or practices for the discourses they challenge; instead, they share their agency in reciprocal relation with those they bring into their videos, and in doing so, re-imagine disability as an embodiment that is basic to human experience (Rice et al., 2017) and contribute to the remaking of a more just world.

Storytellers such as Langdon, Banani, and Phillips identify and challenge the biomedical discourse of disability as tragedy and in need of cure. The cure imperative is evidenced in Langdon's description of being cast as the object of cure, and in Banani's description of her "messy mind" in contrast with the image of a "functional" brain. It is symbolized in the images of pill bottles and hospital rooms and hallways. The biomedical discourse of disability is disrupted in stories that situate difference as something to be valued rather than fixed. This occurs when, for example, Phillips humanizes Joanie and when Banani 
begins to view her own disability as something to be desired. Storytellers also reveal the ways that changing their relationalities with difference challenges impersonalized care practices along with their dehumanizing effects. For Phillips, Cheng, Montgomery, and Graham, the dehumanizing effects of impersonal care practice are realized during encounters with others-Phillips' encounter with Joanie outside of the institutional space they usually occupy, Cheng's by-proxy experience with her Badi-mommy's callous surgeon, Montgomery's eclipsed encounters with clients, and Graham's encounters with young women. Each of these experiences urge the storytellers to critically reflect on their care practices, and prompt them to consider and perhaps adopt alternate practices based on connectivity and inter-corporeality.

Finally, the multimedia stories indicate that the method has the potential to counter truths about professional selves and imagine new ways of performing professionalism in health care encounters. For Zitzelsberger, Lindsay, Banani, and Langdon, this challenge to discourses of professionalism stems from their own experience of falling outside the parameters of the health care professional, often cast as the invulnerable caregiver. Langdon's social work practice, for example, challenges assumptions about health care providers' embodiments, particularly those that equate any deviation from the mythic norm with professional incompetence, even, or especially, when working with a client who calls her professional abilities into question. Each of these encounters with difference compel the storyteller, and possibly the viewer, to dispel myths about mastery and control that are foundational to understandings of professionalism. Although potentially destabilizing, the storytellers' untethering of invulnerability from professional identity might also open space for new types of knowledge and understanding of professionalism. Practices centered around difference and fluidity rather than static homogeneity, and perhaps rooted in less authoritative and aggrandizing, and more inclusive, reciprocal, and modest theories of embodied personhood, engender individual agency.

Throughout the project, each provider-participant welcomed the opportunity to explore and reflect on their own disorientations and re-orientations to difference, provoked, 
according to Csikszentmihalyi (1996) by the unlearning and relearning processes of artmaking. Within each video, storytellers creatively made new meaning of dilemmas and difficult experiences that they can apply to future experiences, something Heron (1996) sees as integral to the creative process. Approaching art-making as a process of discovery re-positions the creator as engaging in an ongoing process of self and worldinquiry and "becoming" (Deleuze \& Guattari, 1972/1983), wherein aspects of that self and world are made not only visible but tangible even as they are always in a process of change. These makers visually, aurally, kinesthetically, viscerally, and narratively convey a profound desire to transform discourses underpinning practice and to enact disability justice perspectives in relationships. Through arts-based storytelling, they depart from mainstream knowledge regimes fueling the cure imperative, maintaining myths of professionalism and invulnerability, and reinforcing the perspective that paternalistic practice is best practice. In these ways, disability arts-informed story-telling can provide new pathways to reflective-feeling and practicing. We acknowledge that those who self-selected into the workshop likely were already interrogating professional discourses and practices, and liberal humanist concepts of embodiment and vulnerability, or were ready to do so.

As a result of this research, we conclude that arts-based methods like multimedia storytelling can facilitate critical reflection in ways that disrupt problematic ableist assumptions guiding health care; however, the tangible implications of these methods for providers' delivery of health care remains to be fully investigated. As part of the workshop process, Re $\cdot V i s i o n$ invited health care providers to complete post-workshop interviews to explore the enduring impacts of their participation on their practice. Although the results from this analysis is beyond the scope of this paper, it is relevant to note that the engagement in, and witnessing of, artistic creation prompted providers in different and competing ways. For some, the experience initiated change in their practice, and for others, feelings of frustration emerged in response to being unable to enact meaningful systemic change. A complete examination of participants' reflections on the process of creating and witnessing multimedia stories regarding difference and disability is currently underway. 


\section{Conclusion}

Throughout the project's workshops, we provided an arts-making space for health care providers to reflect critically on their experiences and understandings of bodymind differences and disabling assumptions operating in health care. In a selection of eight stories, we found that the storytellers questioned imperatives of invulnerability and depersonalized objectivity that govern professional conduct. Through disorienting encounters with difference within and without, storytellers unmask their vulnerabilities as people and as professionals, re-orient to disability as difference, generate reflective feeling-knowledge, and counter received truths. These experiences offer the possibilities for undoing ableist (and other oppressive) concepts and breaking constraining rules of practice. Given its potential to elicit stories of disorienting dilemmas, of vulnerability, and of professionals' and patients' embodiments and health care practices, multimedia storytelling emerges as a promising method for enacting critical disability perspectives in health care. Multimedia storytelling can move health care providers to care about their own and others' experiences of non-normativity by unsettling taken-for-granted assumptions about human embodiment, recasting multiple meanings of disability, and fully acknowledging our shared yet heterogeneous experiences of vulnerabilities. Almost in response to Cheng's poignant question, "How do I bring caring back into our care?" arts-based approaches may help improve care by inviting providers to interrogate the complexities of the inter- and intra-subjective and inter- and intra-corporeal-the in-between spaces created in health care interactions. Attending to difference and what it teaches can help transform both the structural and discursive elements of health care.

\section{Acknowledgments}

We also acknowledge the Center for Digital Storytelling for providing early training in digital storytelling methods, the School of Disability Studies at Ryerson University for the generous donation of accessible workshop space, the University of Guelph for support 
of our methods, and Tangled Arts + Disability, whose funding assisted us in pushing the boundaries of the digital storytelling genre. We also want to thank workshop facilitators Eliza Chandler, jes sachse, Manuela Ferrari, Lindsay Fisher, Fran Odette, Lorna Renooy, Tanya Workman, Janna Brown, Liz Brockest, Hannah Fowlie, Ingrid Mundel, and Rani Sanderson, and the artists and storytellers who participated in our many workshops held throughout the province of Ontario. We especially wish to thank Dawn Matheson and Kimber Sider, who captioned the films and who coached us in the art of audio recording and Wanda Fitzgerald, who undertook the audio description.

\section{Declaration of Conflicting Interests}

The authors declared no potential conflicts of interest with respect to the research, authorship, and/or publication of this article.

\section{Funding}

The authors disclosed receipt of the following financial support for the research, authorship, and/or publication of this article: This research was made possible with generous support from: The Gender and Health Institute of the Canadian Institutes of Health Research (CIHR Grant \# 106597); Canada Research Chair (\# 950-231091); the Canadian Foundation for Innovation (CFI \#35254); and the Leaders Opportunity Fund (\#217843). Principal Investigator Carla Rice.

\section{References}

Bergum V., Godkin D. (2008). Nursing research and the transformative value of art. In Knowles J. G., Cole A. L. (Eds.), Handbook of the arts in qualitative research: Perspectives, methodologies, examples, and issues (pp. 603-613). Los Angeles: Sage. 
Boydell K. M., Volpe T., Cox S., Katz A., Dow R., Brunger F., . . Wong L. (2012). Ethical challenges in arts-based health research. The International Journal of the Creative Arts in Interdisciplinary Practice, 11, 1-17.

Braidotti R. (2016). The critical posthumanities; or, is medianatures to naturecultures as Zoe is to bios? Cultural Politics, 12, 380-390.

Braun V., Clarke V. (2006). Using thematic analysis in psychology. Qualitative Research in Psychology, 3(2), 77-101

Brookfield S. (2009). The concept of critical reflection: Promises and contradictions. European Journal of Social Work, 12, 293-304.

Carroll K., Mesman J. (2018). Multiple researcher roles in video-reflexive ethnography. Qualitative Health Research, 28, 1145-1156.

Chandler E., Changfoot N., Rice C., LaMarre A., Mykitiuk R. (2018). Cultivating disability arts in Ontario. Review of Education, Pedagogy, \& Cultural Studies, 40, 249-264.

Changfoot N., Rice C. (in press). Aging with and into disability: Futurities of new materialisms. In Kelly C., Aubrecht K., Rice C. (Eds.), Aging / Disabiility Nexus. Vancouver: University of British Columbia Press(in press).

Clare E. (2017). Brilliant imperfection: Grappling with cure. Durham and London: Duke University Press.

Crowe M. T., O'Malley J. (2006). Teaching critical reflection skills for advanced mental health nursing practice: A deconstructive-reconstructive approach. Journal of Advanced Nursing, 56, 79-87.

Csikszentmihalyi M. (1996, Summer). How to measure "warding off chaos." The Institute View. 6-7.

Dadich A., Collier A., Hodgins M., Crawford G. (2018). Using positive organizational scholarship in healthcare and video reflexive ethnography to examine positive deviance to new management in healthcare. Qualitative Health Research, 28, 1203-1216.

Deleuze G., Guattari F. (1983). Anti-Oedipus: Capitalism and schizophrenia (Hurley R., Seem M., Lane H. R., Trans.). Minneapolis: University of Minnesota Press. (Original work published 1972) 
Devlin R., Pothier D. (2006). Introduction: Toward a critical theory of dis-citizenship. In Pothier D., Devlin R. (Eds.), Critical disability theory: Essays in philosophy, politics, and law (pp. 1-24). Vancouver: University of British Columbia Press.

Drisko J. W., Maschi T. (2015). Content analysis. New York, NY: Oxford University Press.

Eaton J., Donaldson G. (2016). Altering nursing student and older adult attitudes through a possible selves ethnodrama. Journal of Professional Nursing, 32, 141151.

Eisner E. (2008). Art and knowledge. In Knowles G. J., Cole A. L. (Eds.), Handbook of the arts in qualitative research: Perspectives, methodologies, examples, and issues (pp. 3-13). Los Angeles: Sage.

Fineman M. A. (2008). The vulnerable subject: Anchoring equality in the human condition. Yale Journal of Law and Feminism, 20(1), 1-23.

Haigh C., Hardy P. (2011). Tell me a story-A conceptual exploration of storytelling in healthcare education. Nurse Education Today, 31, 408-411.

Heron J. (1996). Co-operative inquiry. Thousand Oaks, CA: Sage.

Kumari-Campbell F. (2001). Inciting legal fictions: "Disability's" date with ontology and the ableist body of law. Griffith University Review, 10(1), 42-62.

Lambert J. (2013). Digital storytelling: Capturing lives, creating community. Routledge: New York

Lysaught M. T. (2009). Docile bodies: Transnational research ethics as biopolitics. Journal of Medicine \& Philosophy, 34, 384-408.

MacDonnell J., MacDonald G. (2011). Arts-based critical inquiry in nursing and interdisciplinary professional education: Guided imagery, images, narratives, and poetry. Journal of Transformative Education, 9, 203-221.

McCabe J. L., Holmes D. (2009). Reflexivity, critical qualitative research and emancipation: A Foucauldian perspective. Journal of Advanced Nursing, 65, 1518-1526.

Pierre J. (2015). Cripping communication: Speech, disability, and exclusion in liberal humanist and posthumanist discourse. Communication Theory, 25, 330-348. 
Rice C. (2009). Imagining the other? Ethical challenges of researching and writing women's embodied lives. Feminism \& Psychology, 19, 245-266.

Rice C. (2014). Becoming women: The embodied self in image culture. Toronto: University of Toronto Press.

Rice C. (2018). Volatile bodies and vulnerable researchers. In Batacharya S., Wong R. (Eds.), Sharing breath: Embodiment, pedagogy and decolonization. Edmonton: Athabasca University Press. 135-160

Rice C., Chandler E., Changfoot N. (2016). Imagining otherwise: The ephemeral spaces of envisioning new meanings. In Kelly C., Orsini M. (Eds.), Mobilizing metaphor: Art, culture and disability activism in Canada (pp. 54-75). Vancouver: University of British Columbia Press.

Rice C., Chandler E., Harrison E., Ferrari M., Liddiard K. (2015). Project Re•Vision: Disability at the edges of representation. Disability \& Society, 30, 513-527.

Rice C., Chandler E., Liddiard K., Rinaldi J., Harrison E. (2018). Pedagogical possibilities for unruly bodies. Gender and Education, 30, 663-682.

Rice C., Chandler E., Rinaldi J., Liddiard K., Changfoot N., Mykitiuk R., Mundel I. (2017). Imagining disability futurities. Hypatia, 32, 213-229.

Rice C., Dion S., Mundel I., Fowlie H. (in press). Re/turning the gaze: Unsettling settler logics through first-person narrative filmmaking. Feminist Studies.

Rice C., LaMarre A., Changfoot N., Douglas P. (2018). Making spaces: Multimedia storytelling as reflexive, creative praxis. Qualitative Research in Psychology, 118.

Rice C., LaMarre A., Mykitiuk R. (2018). Cripping the ethics of disability arts research. In Macleod C., Marx J., Mnyaka P., Treharne G. (Eds.), Handbook of ethics in critical research: Stories from the field (pp. 257-272). London: Palgrave Macmillan.

Rice C., Mundel I. (2018). Story-making as methodology: Disrupting dominant stories through multimedia storytelling. Canadian Review of Sociology/Revue canadienne de sociologie, 55, 211-231.

Rice C., Mundel I. (2019). Multimedia storytelling methodology: Notes on access and inclusion in neoliberal times. Canadian Journal of Disability Studies, 8(2). 
Rieger K. L., Chernomas W. M. (2013). Arts-based learning: Analysis of the concept for nursing education. International Journal of Nursing Education Scholarship, 10(1), 53-62.

Rioux M. H., Valentine F. (2005). Does theory matter? Exploring the nexus between disability, human rights, and public policy. In Pothier D., Devlin R. (Eds.), Critical disability theory: Essays in philosophy, politics, and law (pp. 47-69). Vancouver: University of British Columbia Press.

Sharma S., Reimer-Kirkham S., Cochrane M. (2009). Practicing the awareness of embodiment in qualitative health research: Methodological reflections. Qualitative Health Research, 19, 1642-1650.

Shildrick M. (1997). Leaky bodies and boundaries: Feminism, postmodernism and (bio)ethics. London: Routledge.

Titchkosky T. (2012). Firing up disability studies: A report from the edges of the human community. Canadian Journal of Disability Studies, 1, 82-108.

Treloar A., McMillan M., Stone T. (2017). Nursing in an imperfect world: Storytelling as preparation for mental health nursing practice. International Journal of Mental Health Nursing, 26, 293-300.

Trevelyan C., Crath R., Chambon A. (2014). Promoting critical reflexivity through artsbased media: A case study. British Journal of Social Work, 44, 7-26.

\section{Author Biographies}

Katharine Viscardis is a PhD candidate at the School for the Study of Canada, Trent University, working under the supervision of Janet Miron. She studies the historic oppression and exclusion of children deemed genetically and socially "unfit" for Canadian citizenship, and the violent legacy of institutionalization. Her dissertation is an emancipatory historiography of the notorious Huronia Regional Centre.

Carla Rice is an award-winning professor and Canada Research Chair at the University of Guelph specializing in embodiment studies, arts-based and creative methodologies, non-normative cultures, and accessibility and inclusion. She founded Re•Vision: The 
Centre for Art and Social Justice as an arts-informed research centre with a mandate to foster inclusive communities, social well-being, equity, and justice. More information about the Re•Vision Centre can be found at: https://projectrevision.ca/.

Victoria Pileggi, PhD, is a graduate from the Department of Family Relations and Applied Nutrition at the University of Guelph. Her scholarship focuses on parent-child relationships in the context of bodily difference, disability, chronic and terminal illness and bereavement. She worked alongside the team at Re•Vision: The Centre for Art and Social Justice as a research associate.

Angela Underhill is a PhD candidate working under the supervision of Dr. Carla Rice in the Department of Family Relations and Applied Nutrition at the University of Guelph, Canada. Angela is also a graduate research assistant at Re $\bullet$ Vision: The Centre for Art and Social Justice. Her scholarship focuses on feminist research approaches to advance social inclusion and equitable care, particularly with respect to sexual and reproductive health and rights.

Eliza Chandler is an assistant professor in the School of Disability Studies at Ryerson University. Chandler's research brings together disability arts, disability studies, and activism, including her co-directorship of Bodies in Translation: Activist Art, Technology, and Access to Life. Chandler is on the board of directors for the Ontario Arts Council and is a practicing curator.

Nadine Changfoot, associate professor of Political Studies at Trent University, engages in collaborative, participatory research with diverse and dis arts, environmental, disability, aging, and healthcare communities. Her research includes: 1) methodology and ethics of arts-based research creation for multimedia storytelling and presentation and 2) cross-sectoral partnerships (state, non-profit sector) for social justice influence and environmental stewardship. She has published widely in feminist, philosophy, qualitative methodology, and community development journals. 
Phyllis Montgomery is a researcher and professor. Her interests involve the well-being of persons living in challenging health and social circumstances.

Roxanne Mykitiuk is professor of Law at Osgoode Hall Law School, York University and director of the Disability Law Intensive clinical program. She directs the Health Law LLM program in the Osgoode Hall Professional Development Program and is co-chair of Enable York. Roxanne is the author or co-author of numerous books, articles and book chapters investigating legal, ethical and social implications of assisted reproduction and genetics and the legal construction and regulation of embodiment and disability. 